\title{
Knowledge and practice of adolescent females about menstruation and menstruation hygiene visiting a public healthcare institute of Quetta, Pakistan
}

\author{
Judy Michael', Qaiser lqbal', Sajjad Haider ${ }^{1}$, Adnan Khalid², Naheed Haque1, Rabia Ishaq ${ }^{1}$, Fahad Saleem',
} Mohamed Azmi Hassali ${ }^{3}$ and Mohammad Bashaar ${ }^{4^{*}}$ (D)

\begin{abstract}
Background: The current study is aimed to assess menstruation-related knowledge and practices of adolescent females visiting a public health care institute of Quetta city, Pakistan.

Methods: A questionnaire-based cross-sectional survey was conducted. Nine hundred and twenty three female adolescents attending general out-patient departments of Mohtarma Shaheed Benazir Bhutto Hospital Quetta, Balochistan, was approached for data collection. Based on the objectives of the study, descriptive analysis was conducted and SPSS V. 21.0 was used for the data analysis.

Results: Demographic characteristics revealed that the mean age of the respondents was 15 years. Mothers' (67\%) were the main source of menstruation-related information. Majority (77.7\%) of our respondents never had a class or session regarding menstruation-related education in their schools. About (44\%) knew that menstruation is a physiological phenomenon while $60.2 \%$ knew that menstrual blood comes from the vagina. Nearly $40 \%$ of our study respondents missed their schools because of menarche. The use of absorbent material was frequent (90\%) among the adolescent females and (68.7\%) used commercially available sanitary napkins/pads. Although majority of the respondents (58.2\%) were not taking baths during menstruation, $80.5 \%$ do cleaned their genitalia with water during menstruation.
\end{abstract}

Conclusion: Female adolescents of our study had certain misconception regarding menstruation because of poor access to health-related education. Education can be provided at healthcare facilities, residential area as well as religious centers. Adolescent reproductive health should be included in the school curriculum; this will influence general reproductive health of females.

Keywords: Knowledge, Practice, Menstruation, Menstruation hygiene, Adolescent

\section{Background}

Menstruation is defined as "periodic discharge of blood from the uterus occurring more or less at regular monthly intervals throughout the active reproductive life of a female" [1]. While menarche is a natural event in girls' life, it is also the beginning of physical and social evolution [2]. Even though the occurrence of regular menstruation is an evidence of a female' excellent reproductive health, the very menstruation is misconstrued as detrimental and

\footnotetext{
* Correspondence: dr.mbashaar@gmail.com

${ }^{4}$ SMART Afghan International Trainings \& Consultancy, Kabul, Afghanistan Full list of author information is available at the end of the article
}

adulterated in many societies [3-5]. Additionally, for certain societies it is prohibited to talk about menstruation and the related issues [6]. Therefore, a natural biological process that dignifies women and girls becomes a subject of shame and annoyance. Such social taboos and myths increase the vulnerability of post pubescent females to unhygienic practices that lead to multiple infections including reproductive and urinary tract [7]. What's more, the societal restriction and scarcity of menstrual-related information results in social dishonor that affect girls' physical and emotional state [6]. This ends in loneliness, school absenteeism, and limited academic, sports and

(c) The Author(s). 2020 Open Access This article is distributed under the terms of the Creative Commons Attribution 4.0 International License (http://creativecommons.org/licenses/by/4.0/), which permits unrestricted use, distribution, and reproduction in any medium, provided you give appropriate credit to the original author(s) and the source, provide a link to the Creative Commons license, and indicate if changes were made. The Creative Commons Public Domain Dedication waiver (http://creativecommons.org/publicdomain/zero/1.0/) applies to the data made available in this article, unless otherwise stated. 
daily activities, hence partially or completely isolating the girl from the society [8].

Shifting our concerns to health-related issues of menstruating girls and women, menstrual sanitation and performance are influenced by multiple factors, however; knowledge about menstruation plays a key role in attaining proper hygiene $[9,10]$. High-quality menstrual hygienic knowledge and practices are essential throughout menstruation time as it improve the self-assurance of females in several ways $[11,12]$. Nevertheless, research and dissemination of accurate information about menstruation has been neglected especially in the developing world for a long time [13]. Chandra-Mouli and Patel in their review reported that girls in majority of the developing world enter puberty with knowledge gaps and mistaken beliefs about menstruation. The authors argued that this lack of knowledge is because adults around them are ill-informed and uncomfortable discussing issues related to sexuality, reproduction and menstruation [14]. These findings are further supported by various studies reported from South Asia where girls had poor knowledge of menstruation and thus do not fully understood the physical process of menstruation [15]. Inline to what is reported; Coast et al. in their scoping review claimed about inadequate knowledge about menstruation and low levels of pre-menarche knowledge among adolescent girls, hence were under-prepared for puberty and menstruation [16].

In addition to poor knowledge towards menstruation, females in low- and middle income countries are normally deprived in making use of the available resources, especially when it comes to menstruation-related hygiene issues. Within this context, no formal guidance from the schools, lack of cultural acceptance of alternative menstrual products, limited economic resources and inadequate water and sanitation facilities are reported as major reasons [17]. Moreover, inadequate WASH (water, sanitation and hygiene) facilities, particularly in schools and other public places are rated as a major obstacle. Collectively, a growing body of evidence shows that girls' inability to manage their menstrual hygiene results in school absenteeism, poor academic performance and episodes of anxiety and depression during or near the menstrual period which in turn has severe societal, economic, healthcare costs [18]. Therefore, evaluating menstrual knowledge and hygiene performance of female adolescents and understanding the knowledge gap is crucial to strengthen sanitized practices during the menstruation cycle [19].

As reported from other developing countries, menstruation is also linked with several misconceptions and poor practices in Pakistan and menstrual practices are clouded by taboos and socio-cultural restrictions [20]. The social stigma attached to menstruation causes many girls to carryout unsafe hygiene practices which in return places a burden on the social, economical and the healthcare system [20]. It is important to highlight that the mentioned evidence reported from Pakistan is from metropolitan cities and there is scarcity of information from remote areas such as from Quetta city, Balochistan [21]. In addition, being a conservative and tribal area, we believe that the social taboos and myths are more prominent as compared to other parts of the country. Keeping the paucity of data from the current study location, our study was aimed to assess the menstruation-related knowledge and practices of adolescent females visiting a public health care institute of Quetta city, Pakistan. Likewise, results of the current study will try to identify menstruation-related issues that are not previously reported in literature.

\section{Methods}

\section{Study design and settings}

A questionnaire-based cross-sectional survey was conducted. Data were collected from patients attending the general outpatient department (OPD) of Mohtarma Shaheed Benazir Bhutto Hospital Quetta (MSBBH), Balochistan. Quetta is the provincial capital and largest city of Balochistan province, Pakistan. Located in northern Balochistan near the Pakistan-Afghanistan border, Quetta is a trade and communication centre between the two countries. This hospital is among the four biggest government hospitals of Quetta city and provides major healthcare facilities to the general population [22].

\section{Study population, sampling and inclusion criteria}

The target population was female adolescents. According to the World Health Organization (WHO) criterion, teenage begins with the onset of puberty and ends when individuality and conduct is maintained. This period expands between 10 and 19 years of age [23]. Proportionate based sampling with a double design effect method was employed for sample size calculation and 940 respondents were targeted for data collection [24].

\section{Data collection tool}

In addition to the demographic information, a structured questionnaire was constructed (Additional file 1) based on extensive literature review [25-27]. The questionnaire was translated in Urdu (Additional file 2, National language and lingua franca of Pakistan) by a linguistic expert; the questionnaire was then translated back into English by another expert to avoid any discrepancy in the two versions. Face and content validity was established by physicians, their opinion was taken into consideration before the pilot study. The questionnaire was subjected to a pilot analysis with 30 participants. The questionnaire was declared reliable with an acceptable alpha value of 0.8 . Data from the pilot study was not included in the field study. 


\section{Data analysis}

SPSS version 21 was used for the analysis of the data. Based on the objectives of the study, descriptive analysis was conducted.

\section{Results}

Data were available from 923 respondents with a response rate of $98.19 \%$. Table 1 demonstrates the demographic characteristics of the study respondents. The mean age of the respondents was 15 years. Majority of the respondents $(241,26.1 \%)$ had the age of 17 years and $51 \%$ had an intermediate level of education. Menarche was reported at the age range of 12-14 years among 73 $\%$ of the respondents.

Table 2 presents the sources of information regarding menstruation. Mothers were the main source of information to the adolescent girls $(618,67 \%)$ before the menstrual period, and $366(39.7 \%)$ of the respondents had information that menstruation bring physical changes. On the contrary, a large number of study respondents $(717,77.7 \%)$ did not attend a class or session about menstruation at their schools.

Table 3 presents knowledge of the study respondents regarding menstruation. A large number of respondents (407, 44.1\%) knew that menstruation is a physiological process and is caused by hormones $(642,69.6 \%)$ while, (207, 22.4\%) had no idea about menstruation and its cause $(140,15.2 \%)$. Five hundred and fifty six girls knew that menstrual blood discharges from vagina, and (237, $25.7 \%$ ) thought that at the age of 13 , girls usually get their first period. Almost $90 \%$ of the respondents knew how to use sanitary pads, and $(560,60.7 \%)$ thought more nutritious diet is required during periods. Two hundred and fifty one $(27.2 \%)$ had menstruation flow of seven days and $(740,80.2 \%)$ thought menstrual blood is unhygienic.

Table 4 indicates problems faced by respondents during menstruation. In response to problems associated with menstruation $(286,31 \%)$ reported back pain, (266, $28.8 \%$ ) reported abdominal pain while, $(230,24.9 \%)$ reported general weakness. Moreover, $61.5 \%$ didn't miss school due to menarche while $53.2 \%$ sometimes missed other activities during menstruation. Almost 50\% avoided certain foods and $70.1 \%$ felt there is foul smell during menstruation.

Table 5 reports the reaction of the respondents towards menstruation. In reaction to first menstruation (399, 43.2\%) felt discomfort and (261, 28.3\%) were scared. Six hundred and thirty four (68.7\%) used commercially made sanitary napkins/pads and (632, 68.5\%) didn't take any medication for the associated problems. To ease the discomfort, rest was taken by $(626,67.8 \%)$ respondents while, $(537,58.2 \%)$ didn't take bath during
Table 1 Characteristics of the study respondents

\begin{tabular}{|c|c|c|}
\hline Characteristics & $N=923$ & $\%$ \\
\hline \multicolumn{3}{|l|}{ Age in Years } \\
\hline 12 & 131 & 14.2 \\
\hline 13 & 26 & 2.8 \\
\hline 14 & 110 & 11.9 \\
\hline 15 & 180 & 19.5 \\
\hline 16 & 109 & 11.8 \\
\hline 17 & 241 & 26.1 \\
\hline 18 & 126 & 13.7 \\
\hline \multicolumn{3}{|l|}{ Educational Level } \\
\hline Middle (8th standard) & 128 & 13.8 \\
\hline Matriculation (10th standard) & 318 & 34.4 \\
\hline Intermediate (12th standard) & 477 & 51.6 \\
\hline \multicolumn{3}{|l|}{ Religion } \\
\hline Islam & 832 & 90.1 \\
\hline Christianity & 84 & 9.1 \\
\hline Hinduism & 7 & 0.8 \\
\hline \multicolumn{3}{|l|}{ Father' Education } \\
\hline Illiterate & 43 & 4.7 \\
\hline Primary & 485 & 52.5 \\
\hline Middle & 45 & 4.9 \\
\hline Matriculation & 59 & 6.4 \\
\hline Intermediate & 291 & 31.5 \\
\hline \multicolumn{3}{|l|}{ Mother's Education } \\
\hline Illiterate & 115 & 12.5 \\
\hline Primary & 344 & 37.3 \\
\hline Middle & 100 & 10.8 \\
\hline Matriculation & 84 & 9.1 \\
\hline Intermediate & 280 & 30.3 \\
\hline \multicolumn{3}{|l|}{ Father's Occupation } \\
\hline Business & 223 & 24.2 \\
\hline Government employee & 486 & 52.7 \\
\hline Non-Government employee & 78 & 8.5 \\
\hline Unemployed & 11 & 1.2 \\
\hline Retired & 33 & 3.6 \\
\hline Others & 92 & 10.0 \\
\hline \multicolumn{3}{|l|}{ Mother's Occupation } \\
\hline Housewife & 712 & 77.13 \\
\hline Government employee & 155 & 16.8 \\
\hline Non-Government employee & 28 & 3.0 \\
\hline Unemployed & 10 & 1.1 \\
\hline Retired & 8 & .9 \\
\hline Others & 10 & 1.1 \\
\hline \multicolumn{3}{|l|}{ Age at menarche } \\
\hline Before 11 Years & 77 & 8.3 \\
\hline
\end{tabular}


Table 1 Characteristics of the study respondents (Continued)

\begin{tabular}{cll}
\hline Characteristics & $N=923$ & $\%$ \\
\hline $12-14$ Years & 675 & 73.1 \\
$15-16$ Years & 171 & 18.5 \\
\hline
\end{tabular}

the menstruation period. Majority (57.6\%) used water to clean their genitalia during menstruation.

Table 6 shows the handling of the used material by the respondents. Used material was discarded by $65 \%$ of the respondents. The dustbins were used to dispose of the material by $75 \%$ of the respondents. Forty five percent of the respondents changed the adsorbent pad twice a day.

\section{Discussion}

Because of the scarcity of literature reported from Quetta city, the current study was aimed to assess the menstruation-related knowledge and practices of adolescent females. Results of our study revealed mothers as major source of menstruation-related information for the respondents followed by their sisters Table 2). Our results are in line to what is reported from India, Nepal and South Africa [28, 29]. Even though the evidence declared menstruation as an uncomfortable topic especially for preteen girls to discuss; mothers and sisters do play a significant role in conveying information about physiological

Table 2 Source of information regarding menstruation

\begin{tabular}{|c|c|c|}
\hline Questions & $N=923$ & $\%$ \\
\hline \multicolumn{3}{|c|}{$\begin{array}{l}\text { Source of knowledge of menstruation before the beginning of the } \\
\text { menstrual period. }\end{array}$} \\
\hline Mother & 618 & 67.0 \\
\hline Elder sister & 172 & 18.6 \\
\hline Aunt & 29 & 3.1 \\
\hline Friend & 76 & 8.2 \\
\hline Media & 7 & 0.8 \\
\hline Others & 21 & 2.3 \\
\hline \multicolumn{3}{|c|}{$\begin{array}{l}\text { Information about menstruation before the beginning of the menstru } \\
\text { period. }\end{array}$} \\
\hline Physical changes & 366 & 39.7 \\
\hline Social Religious restrictions & 59 & 6.4 \\
\hline Bathing processes & 55 & 6.0 \\
\hline Use of the material for absorption & 99 & 10.7 \\
\hline The blood is dirty & 93 & 10.1 \\
\hline The blood comes from the vagina & 80 & 8.7 \\
\hline None & 171 & 18.5 \\
\hline \multicolumn{3}{|c|}{$\begin{array}{l}\text { Before the onset of menstruation, have you had any class session } \\
\text { related to menstruation at your school? }\end{array}$} \\
\hline Yes & 206 & 22.3 \\
\hline No & 717 & 77.7 \\
\hline
\end{tabular}

Table 3 Knowledge of respondents regarding menstruation

\begin{tabular}{lll}
\hline Questions & $N=923$ & $\%$ \\
\hline What is menstruation? & 407 & 44.1 \\
Physiological Process & 28 & 3.0 \\
Disease & 250 & 27.1 \\
Curse of God & 31 & 3.4 \\
Others & 207 & 22.4 \\
Don't know & & \\
What is the cause of menstruation? & 642 & 69.6 \\
Hormones & 114 & 12.4 \\
Curse of God & 19 & 2.1 \\
Disease & 8 & 0.9 \\
Others & 140 & 15.2 \\
Don't know &
\end{tabular}

From which organ does the menstrual blood discharge from?

$\begin{array}{lll}\text { Uterus } & 161 & 17.4 \\ \text { Vagina } & 556 & 60.2 \\ \text { Bladder } & 35 & 3.8 \\ \text { Abdomen } & 14 & 1.5 \\ \text { Others } & 8 & 0.9 \\ \text { Don't know } & 149 & 16.1\end{array}$

At what age do you think girls usually get their first period?

$\begin{array}{lll}10 & 20 & 2.2 \\ 11 & 87 & 9.4 \\ 12 & 233 & 25.2 \\ 13 & 237 & 25.7 \\ 14 & 222 & 24.1 \\ 15 & 70 & 7.6 \\ 16 & 43 & 4.7 \\ 17 & 6 & 0.7 \\ 18 & 5 & 0.5 \\ \text { Do you know how to use a sanitary pad? } & \\ \text { Yes } & 838 & 90.8 \\ \text { No } & 85 & 9.2\end{array}$

Do you know that girls should take more nutritious diet during their periods?

$\begin{array}{lll}\text { Yes } & 560 & 60.7 \\ \text { No } & 118 & 12.8 \\ \text { Don't know } & 245 & 26.5\end{array}$

What is the average duration of your menstruation flow?

$\begin{array}{lll}4 & 193 & 20.9 \\ 5 & 192 & 20.8 \\ 6 & 201 & 21.8 \\ 7 & 251 & 27.2 \\ 8 & 71 & 7.7 \\ 9 & 8 & 0.9\end{array}$


Table 3 Knowledge of respondents regarding menstruation (Continued)

\begin{tabular}{lll}
\hline Questions & $N=923$ & $\%$ \\
\hline 10 & 7 & 0.8 \\
Do you think the menstrual blood is unhygienic? & \\
Yes & 740 & 80.2 \\
No & 183 & 19.8 \\
\hline
\end{tabular}

changes and also about social, emotional and cultural issues. However, the reliability of the menstruation-related information provided by mothers and sisters is questionable as they are not necessarily well equipped to fill gaps in girls' knowledge [14]. It is important to make sure that accurate and reliable information is transferred so that the menstruating girls are prepared to handle menstruationrelated issues. Hennegan et al. in their response to the editorial did mention that majority of the menstruationrelated findings and figures are not substantiated by published peer-reviewed studies and the original sources remain known [30]. Thus, assessment and correction of mothers' and sisters' menstruation-related knowledge is important and should be a matter of concern for healthcare professionals and local support groups.

Table 4 Problems faced by respondents during menstruation

\begin{tabular}{lcc}
\hline Questions & $N=923$ & $\%$ \\
\hline Do you have any problems associated with menstruation? \\
Headache & 59 & 6.4 \\
Vomiting & 44 & 4.8 \\
Weakness & 230 & 24.9 \\
Anorexia & 8 & 0.9 \\
Abdominal pain & 266 & 28.8 \\
Back pain & 286 & 31.0 \\
Others & 30 & 3.3 \\
Have you missed school because of menarche? & \\
Yes & 355 & 38.5 \\
No & 568 & 61.5
\end{tabular}

Do you ever miss other activities (sports, games, social gatherings, etc.) during menstruation?

$\begin{array}{lll}\text { Not at all } & 242 & 26.2 \\ \text { Sometimes } & 491 & 53.2 \\ \text { Rarely } & 85 & 9.2 \\ \text { Always } & 105 & 11.4\end{array}$

Do you avoid certain foods during menstruation?

$\begin{array}{lll}\text { Yes } & 479 & 51.9 \\ \text { No } & 444 & 48.1\end{array}$

Do you think there is foul smell during menstruation?

\begin{tabular}{lll} 
Yes & 647 & 70.1 \\
No & 276 & 29.9 \\
\hline
\end{tabular}

Table 5 Reaction of the respondents towards menstruation

\begin{tabular}{lll}
\hline Questions & $N=923$ & $\%$ \\
\hline What was the reaction to your first menstruation? & 59 & 6.4 \\
Happy & 261 & 28.3 \\
Scared & 399 & 43.2 \\
Discomfort & 194 & 21.0 \\
Emotional disturbance & 10 & 1.1 \\
Others & 356 & \\
What are your eating habits during menstruation? & 38.6 \\
Eat less & 141 & 15.3 \\
Eat more & 426 & 46.2 \\
Eat same amount of food & & \\
Do you use absorbent material during period? & & 88.3 \\
Yes & 815 & 11.7 \\
No & 108 &
\end{tabular}

What absorbent material do you use during menstruation? (You may choose more than one option)

$\begin{array}{lll}\text { Commercially made sanitary napkin/pad } & 634 & 68.7 \\ \text { Homemade pads } & 150 & 16.25 \\ \text { Cotton wool } & 107 & 11.6 \\ \text { Nothing } & 8 & 0.9 \\ \text { Other } & 24 & 2.6\end{array}$

Do you take any medications for problems associated with menstruation?

$\begin{array}{lll}\text { Yes } & 291 & 31.5 \\ \text { No } & 632 & 68.5\end{array}$

What other remedies do you use to ease the discomfort of menstruation?

$\begin{array}{lll}\text { Rest } & 626 & 67.8 \\ \text { Oil massage } & 32 & 3.5 \\ \text { Turmeric milk } & 102 & 11.1 \\ \text { Hot bottle packs } & 113 & 12.2 \\ \text { Others } & 50 & 5.4\end{array}$

When do you prefer to take bath during menstrual period?

$\begin{array}{lll}\text { Daily } & 72 & 7.8 \\ \text { First day } & 56 & 6.1 \\ \text { Second day } & 186 & 20.2 \\ \text { Not during the period } & 537 & 58.2 \\ \text { Others } & 72 & 7.8\end{array}$

Do you clean your genitalia during menstruation?

Yes

$743 \quad 80.5$

No

180

If yes, mostly with what?

Water and soap $\quad 234 \quad 25.4$

Only with water $\quad 532 \quad 57.6$

$\begin{array}{lll}\text { Tissue paper } & 102 & 11.1\end{array}$

$\begin{array}{lll}\text { Towel } & 6 & 0.7\end{array}$ 
Table 5 Reaction of the respondents towards menstruation (Continued)

\begin{tabular}{cll}
\hline Questions & $N=923$ & $\%$ \\
\hline Others & 49 & 5.3 \\
\hline
\end{tabular}

Parallel to our study results, study respondents from Saudi Arabia and India considered menstruation a natural phenomena and a normal physical change [31, 32]. Importantly and as expected, $80 \%$ of our study participants had no prior classes or discussions about menstruation and hygiene at school. The finding is not surprising from a developing world as many girls receive no information or training from schools on how to manage menstruation-related issues [33]. Continuing with our arguments, Kaur et al. discussed that the education sector of developing countries avoids issues related to the menstruation and menstrual hygiene management by considering it a personal matter. Besides, teachers are also not ready to discuss menstruation and menstrual hygiene management with their students. Due to the unsupportive environment, girls remain unfamiliar with menstrual-related issues, and how to take care of personal hygiene [34].

In contrast to the findings of Khanna et al., where 97.5\% of their participants didn't know the source of bleeding, majority of the respondents, in the current study knew that vagina is the organ from where the menstrual blood flows [32]. In our study, 69.6\% respondents knew that menstruation is caused by hormonal changes and adolescent girls had adequate knowledge of

Table 6 Handling of the used material by the study respondents

\begin{tabular}{lcc}
\hline Questions & $N=923$ & $\%$ \\
\hline How do you handle the used material? & 607 & 65.8 \\
Discard it & 226 & 24.5 \\
Wash and discard it & 90 & 9.8 \\
Wash and reuse & \\
Where do you dispose off your used materials? & 692 & 75.0 \\
Dustbin & 39 & 4.2 \\
Drains & 61 & 6.6 \\
Toilets & 107 & 11.6 \\
Burn them & 24 & 2.6 \\
Others & 127 & 13.8 \\
How many times a day do you change the absorbent cloth/pad \\
Once & 424 & 45.9 \\
Twice & 245 & 26.5 \\
Thrice & 127 & 13.8 \\
More than 3 times &
\end{tabular}

the duration of the menstrual cycle, similar to that found in Nigeria [35]. In continuation, Dasgupta and Sarkar in their study revealed that few adolescent females perceived menstrual blood as unhygienic, which is similar to the perception of our participants [9].

Almost $40 \%$ of our study respondents missed their school which is also supported by literature. The relationship between menstruation and school absenteeism is multi factorial. Even though, the present study was not able to identify such factors, we do hypothesize lack of facilities at schools and privacy as major factors. To support our hypothesis, Miiro and colleagues reported that menstruation was strongly associated with school attendance [36]. The United Nations Children's Fund (UNICEF) estimated that about one in ten school-age African girl didn't attend school during menstruation due to lack of cleanliness and separate toilet facilities for female students at schools [37]. Girls are frequently faced with difficulties in managing menstrual periods at school due to lack of adequate privacy and sanitary facilities [38]. As a result girls preferred to stay at home during their menstruation period. In addition to the school, our study respondents also missed out other activities, particularly religious ceremonials. In India, girls were restricted from cooking food and visiting temples during the menstruation period [6]. The influence of religion in the developing world is not to be underestimated and the same influence can be used to answer menstruationrelated issues. Religious leaders of the developing world (Imams, Pandits, Monks and Priests) can be trained and used as a source of evidence based knowledge about menstruation and because of their influence on general public can prove to be a useful resource in handling issue related to menstruation.

Adolescent females of the current study were frightened and felt discomfort during their menarche which is supported by a study conducted in Mashhad, Iran [39]. Our findings are further strengthened as Hennegen et al. in their systematic review and qualitative meta-synthesis stated that menstruation is experienced with discomfort and fear [40]. Furthermore, a large number of our respondents reported usual eating habits during menstruation time. This is against to what is reported by MeyerRochow who explained food taboos are directly related to certain events including menstruation [41]. According to Khan (2000), adolescents and their mothers believed that eating foods considered to be too hot (dry fruits, liver, and eggs) or too cold (ice creams, yogurt, and green leafy vegetables) should be avoided [42]. A possible explanation of this difference is the negligible or poor existence of food taboos in the Pakistani society. Other then what is prohibited by the religion, food is considered as a source of vitality and is the reason of regular heating habits among the adolescent girls during their menstruation time. 
Almost $70 \%$ of our respondents were using commercially available sanitary pads or napkins as an adsorbent material. This finding is against to another study conducted in Pakistan whereby an under usage of napkins due to lack of affordability was reported. The author also reported comfort of using homemade pads [43]. A possible explanation of this difference is the long gap between the two studies and since then much has evolved in terms of knowledge dissemination (especially the evolution of social media). Besides that, our respondents are urban residents while the participants of Khan' study belonged to a rural settings. Nonetheless, the use and reuse of homemade napkins is frequently reported from low and middle income countries [17]. Additionally $80 \%$ of the current study respondents reported to use water and soap for cleaning their genitalia. On the contrary, a study done in Andhra Pradesh revealed that only $4.6 \%$ of the students used water and soap to clean their genitalia that again is related to economical and availability issues [35].

Most of the participants in the present study used commercially available pads and changed their sanitary pads on a daily basis. On average, our respondents used two pads in a day. This is against to the findings of a study conducted in Karachi, Pakistan where the authors claimed that girls in Karachi are either unaware of how to manage menstruation in a hygienic manner or they cannot afford to manage it with modern menstrual materials [20]. In other studies, although the use of pads was preferred over homemade rags and clothes, affordability was rates as a barrier [44, 45]. In certain cases there was no issue of affordability, the pads were thought to be uncomfortable as irritation or rashes were reported by the users. Hence, some female preferred new cloths and towels during menstruation, which were reused after being, washed [46]. Within this context, it is to remember that all those who menstruate need access to their choice of menstrual materials that are affordable, safe and comfortable. We have to remember that menstruation is a normal physiological process in females, but poor hygiene can bring serious health issues like urinary and reproductive tract infection. Therefore, females, especially adolescents, must be psychologically prepared about the physical changes that occur during this period. They should be well aware of the menstruation, menstrual hygiene, and menstrual cycle even before their menarche as well as how to maintain hygiene during the cycle.

\section{Conclusion}

Concluding our study, female adolescents had certain misconceptions regarding menstruation because of poor access to health-related education. These misconceptions impact their practices to manage menstruationrelated issues. Accurate and reliable knowledge can influence attitudes and practices over time, therefore individuals and organizations involved in women' health have to intervene and improve awareness among adolescents regarding menstruation-related issues. Healthcare institute, schools, local societal settings and religious centers should be used to disseminate menstruationrelated information among adolescents that will facilitate the transfer of quality menstruation-related practices to the next generation.

\section{Limitations}

Because of the descriptive nature of study, we were unable to explore the relationship between menarche and school dropout. This should be investigated in another study in near future.

\section{Supplementary information}

Supplementary information accompanies this paper at https://doi.org/10 1186/s12905-019-0874-3.

Additional file 1. Questionnaire used for data collection (English version).

Additional file 2. Questionnaire used for data collection [Urdu (National language of Pakistan) version].

\section{Abbreviations}

MSBBH: Mohtarma Shaheed Benazir Bhutto Hospital; OPD: Outpatient department; UNICEF: United Nations Children's Fund; WASH: Water, Sanitation and hygiene; WHO: World Health Organization

\section{Acknowledgments}

We acknowledge the respondents for their participation in the study.

\section{Authors' contributions}

All authors have contributed equally to the research and this manuscript. JM, $\mathrm{QI}$ and SH conceived the study and framework of the current manuscript. AK and FS conceptualized the study design, and development of the study tool. $\mathrm{NH}$ and $\mathrm{RI}$ were involved in data collection, analysis, and interpretation. $\mathrm{MAH}$ and $\mathrm{MB}$ conducted the literature review, drafted the preliminary manuscript, and supervised the research process. All authors read, critically revised, and approved the final manuscript.

Funding

No funding was received for the study.

\section{Availability of data and materials}

The datasets used and analyzed during the current study are available from the corresponding author at dr.mbashaar@gmail.com on request.

\section{Ethics approval and consent to participate}

The departmental ethics committee at the Faculty of Pharmacy and Health Sciences, University of Balochistan, Quetta approved the study (UoB/Reg:/ GSO/231). Besides, permission was also taken from the Medical

Superintendent of MSBBH Quetta, Balochistan. Written informed consent to participate was also obtained from the parents/guardians of the minors included in this study.

\section{Consent for publication}

This manuscript does not report personal data such as individual details, images, or videos. Therefore, consent for publication is not applicable.

\section{Competing interests}

The authors declare that they have no competing interests.

\section{Author details}

${ }^{1}$ Faculty of Pharmacy \& Health Sciences, University of Balochistan, Quetta, Pakistan. ${ }^{2}$ Combined Military Hospital, Quetta, Pakistan. ${ }^{3}$ School of Pharmaceutical Sciences, Universiti Sains Malaysia, Penang, Malaysia. ${ }^{4}$ SMART Afghan International Trainings \& Consultancy, Kabul, Afghanistan. 
Received: 1 February 2019 Accepted: 27 December 2019

\section{Published online: 06 January 2020}

\section{References}

1. Fingerson L. Girls in power: gender, body, and menstruation in adolescence. NY: State university of New York press; 2016

2. Hennegan J, Sol L. Confidence to manage menstruation at home and at school: findings from a cross-sectional survey of schoolgirls in rural Bangladesh. Cult Health Sex. 2019;1:1-12.

3. Johnston-Robledo I, Sheffield K, Voigt J, Wilcox-Constantine J. Reproductive shame: self-objectification and young women's attitudes toward their reproductive functioning. Women Health. 2007;46(1):25-39.

4. Forbes GB, Adams-Curtis LE, White KB, Holmgren KM. The role of hostile and benevolent sexism in women's and men's perceptions of the menstruating woman. Psychol Women Q. 2003;27:58-63.

5. Seymour K: Tackling menstrual hygiene taboos. Case study, UNICEF 2008. [https:// www.unicef.org/spanish/wash/files/10_case_study_BANGLADESH_4web.pdf]. Accessed 24 Aug 2018.

6. Garg S, Anand T. Menstruation related myths in India: strategies for combating it. J Fam Med Primary Care. 2015;4:184-6.

7. Houston AM, Abraham A, Huang Z, D'Angelo L. Knowledge, attitudes, and consequences of menstrual health in urban adolescent females. J Pediatr Adolesc Gyneco. 2006;19(4):271-5.

8. Singh A, Kiran D, Singh H, Nel B, Singh P, Tiwari P. Prevalence and severity of dysmenorrhea: a problem related to menstruation, among first and second year female medical students. Indian J Physiol Pharmacol. 2008;52(4):389-97.

9. Dasgupta A, Sarkar M. Menstrual hygiene: how hygienic is the adolescent girl? Indian J Community Med. 2008;33(2):77-80.

10. Sudeshna $R$, Aparajita $D$. Determinants of menstrual hygiene among adolescent girls: a multivariate analysis. Natl J Community Med. 2012;3(2):294-301.

11. Prajapati DJ, Shah JP, Kedia G. Menstrual hygiene: knowledge and practice among adolescent girls of rural Kheda District. Natl J Community Med. 2015;13(10):349-53.

12. Karout N. Knowledge and beliefs regarding menstruation among Saudi nursing students. J Nurs Educ Pract. 2016;6(1):23-30.

13. Hennegan J, Dolan C, Wu M, Scott L, Montgomery P. Measuring the prevalence and impact of poor menstrual hygiene management: a quantitative survey of schoolgirls in rural Uganda. BMJ Open. 2016;6:e012596.

14. Chandra-Mouli V, Patel VS. Mapping the knowledge and understanding of menarche, menstrual hygiene and menstrual health among adolescent girls in low- and middle-income countries. Reprod Health. 2017;14:30.

15. Mahon T, Fernandes M. Menstrual hygiene in South Asia: a neglected issue for WASH (water, sanitation and hygiene) programmes. Gend Dev. 2010;18(1):99-113.

16. Coast E, Lattof SR, Strong J. Puberty and menstruation knowledge among young adolescents in low- and middle-income countries: a scoping review. Int J Public Health. 2019;64(2):293-304.

17. Kuhlmann SA, Henry K, Wall LL. Menstrual hygiene management in resource-poor countries. Obstet Gynecol Surv. 2017;72(6):356-76.

18. The World Bank: Menstrual Hygiene management enables women and girls to reach their full potential. 2018. [https://www.worldbank.org/en/ news/feature/2018/05/25/menstrual-hygiene-management]. Accessed 18 Aug 2018.

19. Rana $G$, Jami $H$. Knowledge/awareness and practices related to menstruation among female students: role of mother-daughter relationship. Pak J Psychol Res. 2018;33(2):313-34.

20. Ali TS, Rizvi SN. Menstrual knowledge and practices of female adolescents in urban Karachi, Pakistan. J Adolesc. 2010;33(4):531-41.

21. Government of Balochistan. Quetta district. 2013 [https://www.balochistan. gov.pk/index.php?option=com_content\&view=article\&id=801\&ltemid=1087]. Accessed 1 Aug 2018.

22. Ghaffar R, Iqbal Q, Khalid A, Saleem F, Hassali MA, Baloch NS, Bashir S, Haider S, Bashaar M. Frequency and predictors of anxiety and depression among pregnant women attending tertiary healthcare institutes of Quetta City, Pakistan. BMC Womens Health. 2017;17(1):51.

23. Canadian Paediatric Society. Age limits and adolescents. Paediatr Child Health. 2003:8(9):577.

24. Indicators and methods for cross-sectional surveys of vitamin and mineral status of populations. The Micronutrient Initiative (Ottawa) and the Centers for Disease Control and Prevention (Atlanta). [http://www.who.int/vmnis/ toolkit/mcn-micronutrient-surveys.pdf]. Accessed 28 July 2018.

25. Dhingra R, Kumar A, Kour M. Knowledge and practices related to menstruation among tribal (gujjar) adolescent girls. Stud Ethno Med. 2009;3(1):43-8.
26. Upashe PS, Tekelab T, Mekonnen T. Assessment of knowledge and practice of menstrual hygiene among high school girls in Western Ethiopia. BMC Womens Health. 2015;15:84.

27. Alharbi KK, Alkharan AA, Abukhamseen DA, Altassan MA, Alzahrani W, Fayed A. Knowledge, readiness, and myths about menstruation among students at the Princess Noura University. J Family Med Prim Care. 2018;7:1197-202.

28. Shoor P. A study of knowledge, attitude, and practices of menstrual health among adolescent school girls in urban field practice area of medical college, Tumkur. KLE Univ Health Sci J. 2017;10(3):249-55.

29. Ramathuba DU. Menstrual knowledge and practices of female adolescents in Vhembe district, Limpopo Province, South Africa. Curationis. 2015;38(1):1551.

30. Hennegan J, Torondel B, Phillips-Howard PA, Sommer M, Montgomery P. Time to talk about menstruation: a response. Lancet. 2017;390:845-6.

31. Moawed S. Indigenous practices of Saudi girls in Riyadh during their menstrual period. East Mediterr Health J. 2001;2:197-203.

32. Khanna A, Goyal R, Bhawsar R. Menstrual practices and reproductive problems: a study of adolescent girls in Rajasthan. J Healthc Manag. 2005;7(1):91-107.

33. Tofaris E. Keeping African girls in school with better sanitary care. 2018 https://opendocs.ids.ac.uk/opendocs/handle/20.500.12413/13575. Accessed 20 July 2018.

34. Kaur R, Kaur K, Kaur R. Menstrual hygiene, management, and waste disposal: practices and challenges faced by girls/women of developing countries. J Environ Public Health. 2018; https://doi.org/10.1155/2018/1730964.

35. Akpenpuun JR, Azende P. Menstrual knowledge and practices among adolescents females in Makurdi Metropolis. Glob J Interdiscip Soc Sci. 2014;3(3):113-21.

36. Miiro G, Rutakumwa R, Nakiyingi-Miiro J, Nakuya K, Musoke S, Namakula J, Francis S, Torondel B, Gibson LJ, Ross DA, Weiss HA. Menstrual health and school absenteeism among adolescent girls in Uganda (MENISCUS): a feasibility study. BMC Womens Health. 2018;18:4.

37. Sanitation: The Challenge. United Nations Children's Fund; 2005.

38. McMahon SA, Peter JW, Bethany AC, Alfredo FO, Emily AO, Imelda AO, Richard DR. The girl with her period is the one to hang her head' reflections on menstrual management among schoolgirls in rural Kenya. BMC Int Health Hum Rights. 2011;11(7):1-10.

39. Mohamadirizi S, Kordi M. Association between menstruation signs and anxiety, depression, and stress in school girls in Mashhad in 2011-2012. Iran J Nurs Midwifery Res. 2013;18(5):402-7.

40. Hennegan J, Montgomery P. Do menstrual hygiene management interventions improve education and psychosocial outcomes for women and girls in low and middle income countries? A systematic review. PLoS One. 2016;11(2):e0146985.

41. Meyer-Rochow VB. Food taboos: their origins and purposes. J Ethnobiol Ethnomed. 2009;5:18.

42. Khan, A. Adolescent and reproductive health in Pakistan: A literature review. United Nation Populations Funds and Population Council. 2000. https:// childhub.org/en/child-protection-online-library/khan-2000-adolescents-andreproductive-health-pakistan-literature. Accessed 22 Aug 2018.

43. Khan A. Mobility of women and access to health and family planning services in Pakistan. Reprod Health Matters. 1998;7(14):39-48.

44. Ali TS, Karmaliani R, Salam A, Ladak R, Nancy H, McClure E, Goldenberg R. Hygiene practices during menstruation and its relationship with income and education of women in Hyderabad, Pakistan. Pak J Womens Stud. 2007;13(2):185-99.

45. Fikree FF, Ali T, Durocher JM, Rahbar MH. Health service utilization for perceived postpartum morbidity among poor women living in Karachi. Soc Sci Med. 2004;59(4):681-94.

46. Ali TS, Fikree FF, Rahbar MH, Mahmud S. Frequency and determinants of vaginal infection in postpartum period: a cross-sectional survey from low socioeconomic settlements, Karachi, Pakistan. J Pak Med Assoc. 2006;56(3):99-103.

\section{Publisher's Note}

Springer Nature remains neutral with regard to jurisdictional claims in published maps and institutional affiliations. 